\title{
How many species are there?
}

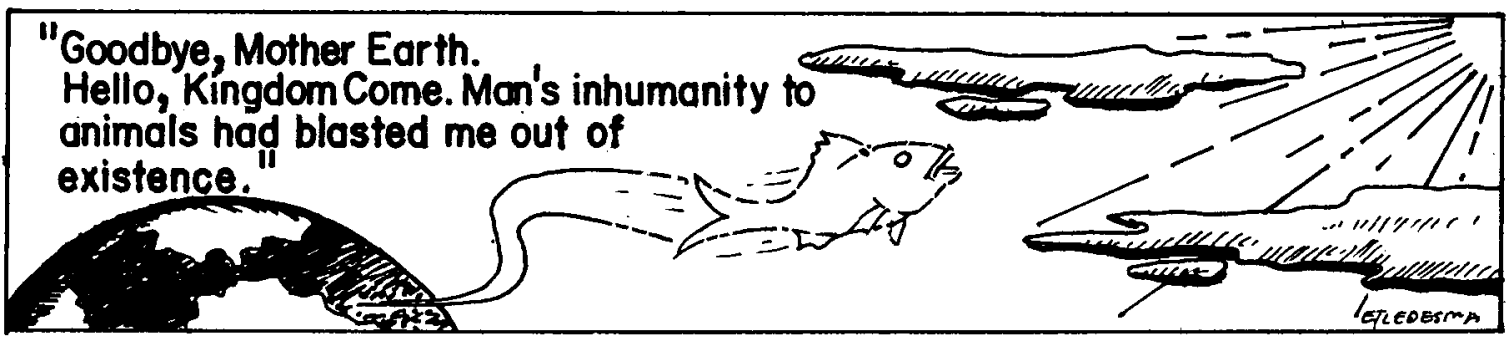

The basis for assessing the importance of biological diversity is an inventory of how many species exist and which species exist where. At the global level, the plants and vertebrates are relatively well known, though major discoveries are reported regularly among fish and some groups of plants. But scientists can only guess at the numbers of many groups of insects (especially the beetles of the tropical forest). There may be as many as 30 million species in total, with most undescribed species living in tropical forests. Mites and nematodes could also number in the hundreds of thousands, if not millions, of species.

Since most estimates of extinctions are based on extrapolations, the lack of precise estimates of total numbers has led to considerable inaccuracy regarding extinction rates. It has been suggested that research on food webs, relative abundance, and the relationship between numbers and physical size of organisms could reveal patterns that would enable the total diversity of plants, animals, and microorganisms to be deduced from appropriate rules.

But the fact remains that basic knowledge of the organisms that make up most ecosystems, especially in the tropics, is woefully inadequate. The Committee on Research Priorities in Tropical Biology concludes that at least a five-fold increase in the number of systematists (above the current estimated 1,500 trained professional systematists competent to deal with any of the tropical organisms) is necessary to deal with a significant proportion of the estimated diversity while it is still available for study. For convenience, many assume that about 10 million species exist, though the final figure is.likely to be $30-50$ million.
Given these limitations, the following represents a summary of the current state of knowledge:

\begin{tabular}{lc} 
Group & $\begin{array}{c}\text { No. of described } \\
\text { species }\end{array}$ \\
\hline Bacteria and & \\
cyanobacteria & \\
Fungi & 4,760 \\
Algae & 46,983 \\
Bryophytes (mosses & 26,900 \\
and liverworts) & 17,000 \\
Gymnosperms (conifers) & 750 \\
Angiosperms (flowering & \\
plants) & 250,000 \\
Protozoans & 30,800 \\
Sponges & 5,000 \\
Corals and jellyfish & 9,000 \\
Roundworms and earthworms & 24,000 \\
Crustaceans & 38,000 \\
Insects & 751,000 \\
Other anthropods and & \\
$\quad$ minor invertebrates & 132,461 \\
Mollusks & 50,000 \\
Echinoderms & 6,100 \\
Fishes (teleosts) & 19,056 \\
Amphibians & 4,184 \\
Reptiles & 6,300 \\
Birds & 9,198 \\
Mammals & 4,170 \\
\hline Total & $1,435,662$ \\
\hline & $5 p e c i e s$ \\
\hline & \\
\hline &
\end{tabular}

Reference: McNeely, J.A. et al. 1990. Conserving the World's Biological Diversity. International Union for Conservation of Nature and Natural Resources, Gland, Switzerland; Wildlife Research Institute, World Wildlife Fund, Conservation International, and the World Bank, Washington, D.C. 